REVIEW

\title{
Unnecessary repeat requesting of tests: an audit in a government hospital immunology laboratory
}

\author{
J Kwok, B Jones
}

J Clin Pathol 2005;58:457-462. doi: 10.1136/icp.2004.021691

Unnecessary repeat requesting of tests can make up a large proportion of a laboratory's workload. This audit set out to establish the size of this problem and to identify the circumstances under which these repeat requests were made in a government tertiary hospital immunology laboratory. The numbers of tests for immunoglobulin measurement, common autoantibodies, and tumour markers that were repeated over a 12 month period were analysed by interrogating the Delphic laboratory computer system using a management information system for raw data enquiry protocol. Repeat requests within 12 weeks of a previous request made up $16.78 \%$ of the total workload. The total cost of the tests was estimated at US\$ 132151. The waste of technician time and reagents as a result of unnecessary repeat testing is excessive. Many of these tests might be eliminated with the use of interventions such as computerised reminders.

See end of article for authors' affiliations

Correspondence to:

Dr J Kwok, Department of Pathology, Queen Mary Hospital, Pokfulam Road, Hong Kong; kwoksy@ha. org.hk

Accepted for publication 31 August 2004
$\mathrm{T}$ he utilisation of laboratory services has increased during the past several decades in many health care jurisdictions around the world. ${ }^{1-3}$ Studies have found up to a 17 fold variation in the number of tests that physicians order. ${ }^{4}$ In our immunology laboratory, the total number of tests performed annually increased by 63\% between 1995 and 2003.

The appropriate use of laboratory tests is necessary for optimal patient care. Increased laboratory use is appropriate if it allows accurate diagnoses to be made, ideal treatment to be identified and monitored, accurate prognoses to be established, and patients' hospital stays to be shortened. Physician ordering practices have been analysed extensively, ${ }^{6-9}$ and inappropriate test ordering found to be a primary reason for increased laboratory use. ${ }^{10-16}$ Over ordering may be the result of inexperience or lack of knowledge about the appropriate use of tests, ${ }^{17}{ }^{18}$ failure to check previous results, test ordering routines that are difficult to change, or fear of errors of omission and litigation. Moreover, patients actively ask for tests and often attach greater value to test results than is justified. ${ }^{19}{ }^{20}$ "The appropriate use of laboratory tests is
necessary for optimal patient care."

Performing unnecessary tests may have adverse effects-for example, unnecessary exposure to toxic treatments or false positive results that may induce fear and anxiety in patients, ${ }^{21}{ }^{22}$ or may result in a cascade of further unnecessary testing.

Laboratory tests cost the health care system large amounts of money, ${ }^{23-26}$ and their inappropriate use may be associated with other inefficiencies in health care delivery. Identifying inadequacies in the use of laboratory services may disclose problems in other areas of health care.

As with other areas of physician behaviour, ${ }^{27} 28$ improving the use of laboratory tests has been difficult. ${ }^{29}$ Repeat testing is one component of laboratory utilisation that could be modified..$^{30} 31$ When a previous result is not available or the ordering physician is unaware that the test was performed previously, 32 information technology can present previous test results ${ }^{33}$ or give the probability that a test will be abnormal. ${ }^{34}$

One change with great potential to affect physician behaviour is computerised physician order entry. ${ }^{35-37}$ Alerts can be issued automatically at the time of test requesting if that test was requested recently. However, the degree to which alerts have affected physician behaviour has been variable. ${ }^{38}$

Many attempts have been made to change test ordering performance and bring it into line with existing guidelines on optimal testing. Results have been mixed but showed that successful strategies require a well balanced combination of interventions. ${ }^{27}$ 39-42

Many serum rheumatological tests have become available relatively recently. As a result, some physicians are not fully aware of the indications, sensitivity, specificity, cost, and clinical usefulness of these tests. Several stu$\operatorname{dies}^{43-46}$ have suggested that overuse of common serum rheumatological tests-including antinuclear antibody (ANA), rheumatoid factor (RF), and many other autoantibody tests-leads to unnecessary referrals and further laboratory investigations. Failure to use these tests in a knowledgeable and thoughtful manner can result in diagnostic confusion and increased costs. $^{47}$

Tumour markers are widely used in the diagnosis and management of cancer. Tumour

Abbreviations: ADNA, anti-double stranded DNA antibodies; AENA, anti-extractable nuclear antigen antibodies; AFP, $\alpha$ fetoprotein; AGPC, anti-gastric parietal cell antibodies; $A M A$, antimitochondrial antibodies; ANA, antineutrophil antibodies; ASM, antismooth muscle antibodies; CEA, carcinoembryonic antigen; PSA, prostate specific antigen; RF, rheumatoid factor 
Table 1 Test unit costs, repeat intervals, and turnaround times

\begin{tabular}{lllll}
\hline Test & TAT (days) & Unit cost* & Repeat interval & References for justification of repeat interval \\
\hline ANA & 3 & 21 & 4 weeks & $44-46$ \\
AENA & 4 & 13 & 4 weeks & $44-46$ \\
ADNA & 6 & 11 & 6 weeks to 6 months & $6-12$ weekly for active \\
RF & 3 & 4 & 4 weeks & $6-12$ monthly for inactive 50 \\
AMA & 8 & 9 & 4 weeks & Except in Sjögren's syndrome ${ }^{44-46} 5152$ \\
ASM & 8 & 9 & 4 weeks & $53-60$ \\
AGPC & 8 & 9 & 4 weeks & $53-60$ \\
IgG, IgA, lgM & 3 & 7 & 4 weeks & 61,62 \\
AFP & 3 & 6.5 & 12 weeks & 63,64 \\
CEA & 3 & 6.5 & 12 weeks & $65-69$ \\
CA15.3 & 3 & 7.5 & 12 weeks & $65,67,70-77$ \\
PSA & 4 & 7.5 & 12 weeks & $67,70,78$ \\
\hline
\end{tabular}

${ }^{*}$ In US\$.

ADNA, anti-double stranded DNA antibodies; AENA, anti-extractable nuclear antigen antibodies; AFP, $\alpha$ fetoprotein; AGPC, anti-gastric parietal cell antibodies; AMA, anti-mitochondrial antibodies; ANA, antinuclear antibodies; ASM, anti-smooth muscle antibodies; CEA, carcinoembryonic antigen; PSA, prostate specific antigen; RF, rheumatoid factor; TAT, turn around time.

markers have five potential uses in patient care: screening, diagnosis, establishing prognosis, monitoring treatment, and detecting relapse. The value of a marker in a particular malignancy also depends on the effectiveness of the treatment available. Tumour markers have been used to screen for occult cancer but have proved to be valuable only in selected cancers. An extreme increase in a marker often indicates a poor prognosis, and in some malignancies can indicate the need for more aggressive treatment. Tumour markers have their greatest value when used to monitor treatment in patients with widespread cancer. Nearly all markers show some correlation with the clinical course of disease, with marker increases at all stages declining to normal after a curative intervention.

\section{"One change with great potential to affect physician behaviour is computerised physician order entry"}

Unnecessary repeat requesting of tests can make up a large proportion of a laboratory's workload. This audit set out to establish the size of this problem in a government tertiary hospital immunology laboratory. This setting has not been studied previously and is informative because most immunology tests are slow to change, so that repeat testing within a short time serves no useful clinical purpose. We also tried to identify the circumstances under which these repeat requests were made because this information might suggest what action could be taken to reduce the rate of such requests.

\section{METHODS}

\section{Setting}

The clinical immunology laboratory, in the department of pathology, Queen Mary Hospital is a tertiary immunology laboratory operating under the Hospital Authority of Hong Kong. Although it primarily serves the Hong Kong West cluster with a population of half a million people, approximately $20 \%$ of requests are from other hospital authority hospitals. The study samples included all the laboratory requests received from all sources during a 12 month period from October 2001 to September 2002.

\section{Test selection and definitions}

We analysed the use of eight tests commonly requested by rheumatologists, the results of which are unlikely to change greatly over short time periods, namely: IgG, IgA, and IgM values; ANA; antimitochondria antibodies (AMA); antigastric parietal cell antibodies (AGPC); anti-smooth muscle antibodies (ASM); anti-double stranded DNA antibodies (ADNA); anti-extractable nuclear antigen antibodies (AENA); and RF. Immunoglobulin concentrations ordered for the diagnosis or monitoring of myeloma were excluded. We also analysed the following tumour marker tests, which may be more variable over time and are useful in disease monitoring: $\alpha$ fetoprotein (AFP), carcinoembryonic antigen (CEA), CA15.3, and prostate specific antigen (PSA). All these tests are either frequently requested, labour intensive, or high cost. AFP ordered for the monitoring of hepatocarcinoma was excluded. We analysed requesting patterns over a 12 month period, identifying tests that were repeated within one day, one week, one month, and three months of a previous request by interrogating the Delphic laboratory computer system using a management information system for raw data enquiry protocol.

A literature review was performed to identify published guidelines for performing each test, and test specific time intervals within which a repeat test was unlikely to show clinical change were developed (table 1). The recommended

Table 2 Requests for common immunological tests over a 12 month period

\begin{tabular}{|c|c|c|c|c|c|c|c|c|c|c|}
\hline & \multicolumn{9}{|c|}{ Weeks between requests } & \multirow{2}{*}{$\begin{array}{l}\text { No. of annual } \\
\text { requests }\end{array}$} \\
\hline & Same day & $<1$ & $>1-2$ & $>2-4$ & $>4-8$ & $>8-12$ & $>12-24$ & $>24-48$ & Total & \\
\hline ANA & 32 & 77 & 54 & 129 & 193 & 161 & 310 & 136 & 1092 & 6161 \\
\hline AENA & 15 & 58 & 29 & 48 & 73 & 48 & 106 & 63 & 440 & 4742 \\
\hline ADNA & 14 & 107 & 263 & 644 & 967 & 667 & 1016 & 151 & 3829 & 6150 \\
\hline RF & 23 & 37 & 28 & 68 & 85 & 67 & 116 & 65 & 489 & 3843 \\
\hline AMA & 1 & 9 & 7 & 20 & 29 & 36 & 101 & 30 & 233 & 1427 \\
\hline ASM & 1 & 12 & 9 & 20 & 32 & 37 & 96 & 37 & 244 & 1312 \\
\hline AGPC & 1 & 4 & 3 & 0 & 3 & 1 & 2 & 1 & 15 & 501 \\
\hline $\lg G, \lg A, \lg M$ & 39 & 251 & 271 & 603 & 699 & 339 & 519 & 168 & 2889 & 7059 \\
\hline
\end{tabular}

ADNA, anti-double stranded DNA antibodies; AENA, anti-extractable nuclear antigen antibodies; AGPC, anti-gastric parietal cell antibodies; AMA, antimitochondrial antibodies; ANA, antinuclear antibodies; ASM, anti-smooth muscle antibodies; RF, rheumatoid factor. 
Table 3 Percentage of all repeated requests within specified time frame for common immunological tests over a 12 month period

\begin{tabular}{|c|c|c|c|c|c|c|c|c|}
\hline & Same day & 1 week & 4 weeks & 12 weeks & 26 weeks & 52 weeks & Total $^{*}$ & $\begin{array}{l}\text { No. of annual } \\
\text { requests }\end{array}$ \\
\hline ANA & 2.9 & 10 & 26.7 & 59.2 & 87.6 & 100 & 1092 (17.7) & 6161 \\
\hline AENA & 3.4 & 16.6 & 34.1 & 61.6 & 85.78 & 100 & 440 (9.3) & 4742 \\
\hline ADNA & 0.4 & 3.2 & 26.9 & 69.5 & 90.1 & 100 & 3829 (62.3) & 6150 \\
\hline RF & 4.7 & 12.3 & 31.9 & 63.0 & 86.7 & 100 & 489 (12.7) & 3843 \\
\hline AMA & 0.4 & 4.3 & 15.9 & 43.8 & 87.1 & 100 & 233 (16.3) & 1427 \\
\hline ASM & 0.4 & 5.3 & 17.2 & 45.5 & 84.8 & 100 & 244 (18.6) & 1312 \\
\hline AGPC & 0.6 & 33.3 & 53.3 & 80.0 & 93.3 & 100 & $15(3)$ & 501 \\
\hline $\lg G, \lg A, \lg M$ & 1.3 & 10.0 & 40.3 & 76.2 & 94.2 & 100 & $2889(40.9)$ & 7059 \\
\hline
\end{tabular}

ADNA, anti-double stranded DNA antibodies; AENA, anti-extractable nuclear antigen antibodies; AGPC, anti-gastric parietal cell antibodies; AMA, antimitochondrial antibodies; ANA, antinuclear antibodies; ASM, anti-smooth muscle antibodies; RF, rheumatoid factor.

*Percentage of annual requests in parenthesis.

frequencies of checking tumour markers used in our study in different cancers are based on practice guideline sources, including those of the National Academy of Clinical Biochemistry; European Group on Tumour Markers; Standards, Options and Recommendations Project; Scottish Intercollegiate Guideline Network; and American Joint Committee on Cancer. Table 1 also shows the turnaround times for our laboratory.

An unnecessary repeat test was defined as one that followed a preceding test of the same type before the test specific time interval had elapsed, and a redundant test as an early repeat test that might be eliminated with little loss of information.

\section{ANALYSIS}

For each test, the registered patient's database records were used to perform a list screen to identify tests that might have been performed earlier than the test specific interval. The patient's records included basic demographic information for each patient, either in the hospital or outpatient setting.

To estimate the proportion of early repeats that was redundant for a given test, the proportion of tests that met the early repeat criteria was determined.

To estimate the potential cost savings if all these redundant tests were eliminated, the number of tests was multiplied by the 2002 costs/test, which were calculated as follows:

$$
\begin{aligned}
& \text { Cost } / \text { test }=\left\{\frac{\text { Staff salaries/year* }}{\text { Total WLU/year }}\right\} \\
& \times \text { WLU/test }+ \text { Reagent cost/test } \\
& { }^{*} \text { US\$ 0.85/WLU (workload unit). }
\end{aligned}
$$

\section{RESULTS}

In total, 9231 requests for immunoglobulin measurement, RF, ANA, AMA, ASM, AGPC, ADNA, and AENA were repeated during the year, making up $29.6 \%$ of the total number of these tests performed (table 2). Repeat requests within 12 weeks of a previous request made up $14.6 \%$ of the total number of tests. For individual tests, the corresponding proportions were: autoantibody screens, $12.9 \%$; RF, $8.0 \%$; and immunoglobulins, $31.2 \%$ (table 3). In total, 19102 repeat requests were made for tumour markers (table 4). Repeat requests made within 12 weeks of a previous request accounted for $21.2 \%$ of the total number of requests for these tests. For individual tumour marker tests, the corresponding proportions were: AFP, 21.4\%; CEA, 13.4\%; CA15.3, 29.6\%; and PSA, 20.5\% (table 5).

The total cost of tests repeated within 12 weeks of a previous test was estimated at US\$ 132151.

Shorter time periods were also analysed. Repeat autoantibody tests are not indicated within a four week period, ${ }^{44-46}$ yet $5.3 \%$ of autoantibody screens and $4.1 \%$ of RF tests were repeated within this time. The total cost of tests repeated within four weeks of a previous test was estimated at US\$ 29527 . Tests repeated within a two week time period accounted for $3.2 \%$ of the total workload for the year.

Possible reasons for repeat testing were sought within the data collected. Because more than $95 \%$ of the requests are from Queen Mary Hospital or hospital authority hospitals, tests performed in general practice and then repeated on referral to hospital are minimal. In addition, only $5-10 \%$ of unnecessary repeats were because of a change of consultant or location within the hospital. More than $90 \%$ of all repeated tests were performed by the same consultant team in the same location. Clearly, hospital consultants and their teams should be the target of any intervention to change this requesting behaviour. Feedback of individual test use data to consultants has been shown to reduce overall request frequency for haematology and clinical chemistry tests. ${ }^{10} 48$ Whether this results in an improvement in clinical care has been contested, ${ }^{49}$ but with the tests we have analysed there is no doubt that frequent repeats are unnecessary.

\section{DISCUSSION}

Pathologists are required to identify areas of potential

\begin{tabular}{|c|c|c|c|c|c|c|c|c|c|c|}
\hline & \multicolumn{9}{|c|}{ Weeks between requests } & \multirow{2}{*}{$\begin{array}{l}\text { No. of annua } \\
\text { requests }\end{array}$} \\
\hline & Same day & $<1$ & $>1-2$ & $>2-4$ & $>4-8$ & $>8-12$ & $>12-24$ & $>24-48$ & Total & \\
\hline AFP & 66 & 473 & 648 & 1159 & 1430 & 1377 & 3096 & 1968 & 10217 & 24072 \\
\hline CEA (colon cancer) & 11 & 90 & 85 & 251 & 554 & 727 & 1590 & 500 & 3808 & 10875 \\
\hline CEA (breast cancer) & 6 & 9 & 25 & 58 & 91 & 282 & 654 & 161 & 1286 & 5438 \\
\hline CA15.3 & 2 & 27 & 67 & 329 & 457 & 475 & 912 & 290 & 2559 & 4582 \\
\hline PSA & 9 & 26 & 35 & 150 & 266 & 179 & 400 & 167 & 1232 & 3244 \\
\hline
\end{tabular}
improvement in laboratory operation, noting tests that are

Table 4 Requests for tumour markers over a 12 month period 
Table 5 Percentage of all repeated requests within specified time frame for tumour markers over a 12 month period

\begin{tabular}{|c|c|c|c|c|c|c|c|c|}
\hline & $\begin{array}{l}\text { Same } \\
\text { day }\end{array}$ & 1 week & 4 weeks & 12 weeks & 26 weeks & 52 weeks & Total $^{*}$ & $\begin{array}{l}\text { No. of annual } \\
\text { requests }\end{array}$ \\
\hline AFP & 0.6 & 5.3 & 23.0 & 50.4 & 80.8 & 100 & $10217(42.4)$ & 24072 \\
\hline CEA (colon cancer) & 0.3 & 2.7 & 11.5 & 45.1 & 86.9 & 100 & $3808(35.0)$ & 10875 \\
\hline CEA (breast cancer) & 0.5 & 1.2 & 7.6 & 36.6 & 87.5 & 100 & $1286(23.6)$ & 5438 \\
\hline CA 15.3 & 0.1 & 1.1 & 16.6 & 53.0 & 88.7 & 100 & $2559(55.8)$ & 4582 \\
\hline PSA & 0.7 & 2.8 & 17.9 & 24.0 & 86.4 & 100 & $1232(38.0)$ & 3244 \\
\hline
\end{tabular}

AFP, $\alpha$ fetoprotein; CEA, carcinoembryonic antigen; PSA, prostate specific antigen.

*Percentage of annual request in parenthesis.

high volume, expensive, difficult to perform, or of questionable medical benefit. As health carers strive to reduce the cost of an episode of care, the laboratory may, ironically, incur additional costs by providing testing that contributes to earlier diagnosis and better disease management, although any consequent decrease in the length of stay in hospital will of course be cost effective. Laboratory staff must work with physicians and the institution to design processes that reduce cost through decreased use and improved decision making, and by the selection of clinically relevant, cost effective technologies and testing protocols. To evaluate new methods and equipment, laboratory expenses must be refined to include workload recording of individual tests and cost accounting of supplies, equipment, facilities, and reagents.

Guidelines are urgently needed to assist test ordering. Inappropriate tests are costly, generate more inappropriate tests, and affect patient care. Ultimately, it is the pathologist's job to help clinicians to order the right tests, at the right time, in the right order.

Tests that are repeated too early to provide useful information represent only a small proportion of those that are unnecessary or of marginal yield. However, they form a group that is relatively easy to target. In the study of Bates et $a l^{80} 8.6 \%$ of a defined group of commonly performed chemistry tests appeared to be redundant.

Table 6 shows some possible reasons for unnecessary repeat testing. Test duplication may occur simply because the requesting clinician is not aware that the test has already been performed. This should not have been a major justification for test repeats in our study, in which all tests had short turnaround times, of three to eight days (table 1). Where no result is immediately available a new test is ordered. Computerised physician ward ordering systems have been implemented in a variety of sites, ${ }^{35-37}$ and have been found to improve efficiency of care. ${ }^{37}$ Such behaviour might be modified by an interactive generic clinical request system that gives details of tests already ordered, and may also block the re-requesting of selected tests within a specified time frame. Computerised reminders, delivered to the ordering physician at the time a test is ordered, hold great potential for reducing the number of redundant tests. ${ }^{35}$ To be most effective, these reminders should be delivered in situations in which there is a high likelihood that they will be followed.

Table 6 Possible reasons for repeat testing

Not aware that the test has already been performed

Poor understanding of half lives of tumour markers

Lack of appreciation of the value of repeated testing of autoantibodies Overemphasis on surveillance

Inexperience or lack of knowledge about the appropriate use of tests

Failure to check previous results

Test ordering routines that are difficult to change

Fear of errors of omission and litigation

Patients actively ask for tests
Our study was performed in part to prepare for the implementation of alerts about potentially redundant tests in our hospital.

\section{"Ultimately, it is the pathologist's job to help clinicians to} order the right tests, at the right time, in the right order"

However, even computerised alerts will be ignored if clinicians do not accept the recommendation, so our results also have implications for physician education. Some of the redundant tests probably resulted from a poor understanding of the half lives of tumour markers or a lack of appreciation of the value of repeated testing of autoantibodies. Others may have been caused by an overemphasis on surveillance. All of these issues may be addressed through education, and physicians in clinical laboratories should become more involved in bringing them to medical schools and residency programmes, and to practising physicians.

Tumour markers and autoantibody tests should be readily addressable with computerised reminders at the time of ordering, unless computerised ordering systems are bypassed in obtaining these tests. It may be appropriate to repeat certain tests more frequently in lieu of rejected requests-for example, to guide chemotherapy of multiple myeloma using $\beta 2$ microglobulin values rather than immunoglobulin and/or paraprotein values.

It is complicated to assess the economic impact of the elimination of tests identified as redundant. Assuming that a system could prevent all such redundant tests from being performed, and assuming no adverse impact on patient care, total costs in our laboratory could be trimmed by about US\$ 132 262.5/year. These savings could be used to employ additional staff who could contribute to the performance of income generating activities, such as clinical trials. It is only by reducing laboratory costs and increasing income that resources can be freed for the development of new "cutting edge" services.

Our study was performed at only one large university hospital laboratory, so that it may not be possible to generalise to other settings. A randomised trial is required to determine how many of these tests can actually be eliminated. Our projections were based on a small sample of the performed tests that may not have been representative of the entire range of tests. Another limitation is that clinical changes may have occurred that were not documented in the medical record. The tests that were analysed are those that are frequently used and for which published guidelines or recommendations exist. The usefulness of repeating other tests is an area for further investigation. Finally, even for the tests included in our study, more stringent intervals may make sense. Our criteria for defining an early repeat were usually more generous than those published in the literature. For example, most autoantibody tests not used in disease activity monitoring are never justified for repeat when positive, but may be repeated when negative. ${ }^{50-62}$ We have 
used an interval of four weeks for these tests, whether positive or negative, based on the half life of IgG (23 days).

"Combinations of practice guidelines, modifications to the laboratory requisition form, and funding policy changes were associated with significant decreases in the use of several tests"

Interventions to improve laboratory utilisation include feedback, physician education, laboratory requisition form changes, policies concerning laboratory test ordering, and financial incentives. ${ }^{81}$ Studies have concluded that educational interventions have mixed effects on laboratory test use. ${ }^{29}{ }^{82-84}$ Significant decreases in test rates were seen when laboratory requisition forms were modified to contain fewer test choices, ${ }^{85}$ presented tests in physiologically sensible groups, ${ }^{86} 87$ or required ordering physicians to justify the need for the test. ${ }^{88}$ Some studies have shown that policies that prohibit particular tests in particular situations ${ }^{83}$ or limit the allowable total number of investigations ${ }^{89}$ are effective in decreasing use. However, their effect decays with time if the intervention programme is not continued. ${ }^{90}$ Combinations of practice guidelines, modifications to the laboratory requisition form, and funding policy changes were associated with significant decreases in the use of several tests. The effects of these interventions were persistent and avoided a large number of tests, resulting in decreased costs. ${ }^{91}$

In our audit, there was no attempt to determine whether the tests were ordered appropriately. Some of the repeated tests may have been requested to confirm a previous abnormal result, but this too is a practice that we would not encourage unless the results truly conflict with the clinical findings. In such cases, the physician should consult the laboratory directly, in response to which senior immunologists should maintain close involvement with the retesting procedure. Physicians should become familiar with all the validation processes in place for ensuring accuracy of reported test results, and laboratory scientists must be able to provide convincing evidence that the laboratory's results are trustworthy.

A population based assessment is optimal for the accurate measurement of repeat laboratory testing. This allows laboratory use to be studied for everyone within a geographical area, rather than within a particular hospital or health services organisation. A population based analysis allows laboratory use to be followed even when patients transfer between different sectors of the healthcare system, such as from the community to the hospital. Finally, a population based analysis produces unbiased utilisation rates because a true denominator (that is, all the people in a particular area) rather than a "pseudodenominator" (all the people who had

Take home messages

- We carried out an audit to assess the extent of unnecessary repeat testing and to identify the circumstances under which repeat requests were made in a government tertiary hospital immunology laboratory

- Repeat requests for immunoglobulin measurement, common autoantibodies, and tumour markers within 12 weeks of a previous request made up $16.78 \%$ of the total workload, with an estimated cost of US\$ 132151

- This excessive waste of technician time and reagents might be reduced by the use of interventions such as computerised reminders a laboratory test) is used. This is necessary for a meaningful comparison between repeat laboratory testing and the utilisation of other health services. Generic clinical request systems have the potential to help clinicians screen for inappropriate, ineffective, potentially dangerous, or unnecessary tests.

\section{Authors' affiliations}

J Kwok, B Jones, Clinical Immunology Division, Department of Pathology, Queen Mary Hospital, Pokfulam Road, Hong Kong

\section{REFERENCES}

1 Danzon PM, Manning WG Jr, Marquis MS. Factors affecting laboratory test use and prices. Health Care Financ Rev 1984;5:23-32.

2 Fowkes FG, Catford JC, Logan RF. Containing the use of laboratory tests. BMJ 1985;290:488-90.

3 Showstack JA, Schroeder SA, Matsumoto MF. Changes in the use of medical technologies, 1972-1977: a study of 10 inpatient diagnoses. N Engl J Med 1982;306:706-12.

4 Epstein AM, McNeil BJ. Physician characteristics and organizational factors influencing use of ambulatory tests. Med Decis Making 1985;5:401-15.

5 Schroeder SA, Kenders K, Cooper JK, et al. Use of laboratory tests and pharmaceuticals. Variation among physicians and effect of cost audit on subsequent use. JAMA 1973;225:969-73.

6 Bugter-Maessen AM, Winkens RA, Grol RP, et al. Factors predicting differences among general practitioners in test ordering behaviour and in the response to feedback on test requests. Fam Pract 1996;13:254-8.

7 Epstein AM, McNeil BJ. Relationship of beliefs and behavior in test ordering. Am J Med 1986;80:865-70.

8 Hartley RM, Epstein AM, Harris CM, et al. Differences in ambulatory test ordering in England and America. Role of doctors' beliefs and attitudes. Am J Med 1987;82:513-17.

9 Williams SV, Eisenberg JM, Pascale LA, et al. Physicians' perceptions about unnecessary diagnostic testing. Inquiry 1982;19:363-70.

10 Bareford D, Hayling A. Inappropriate use of laboratory services: long term combined approach to modify request patterns. BMJ 1990;301:1305-7.

11 Beck JR. Does feedback reduce inappropriate test ordering? Arch Pathol Lab Med 1993; 117:33-4.

12 Bush TM, Shlotzhauer TL, Grove W. Serum complements. Inappropriate use in patients with suspected rheumatic disease. Arch Intern Med 1993;153:2363-6

13 Hyams KC. Inappropriate urine cultures in hospitalized patients receiving antibiotic therapy. Arch Intern Med 1987; 147:48-9.

14 Perraro F, Rossi P, Liva C, et al. Inappropriate emergency test ordering in a general hospital: preliminary reports. Qual Assur Health Care 1992;4:77-81.

15 Tabriz MS, Riederer K, Baran J Jr, et al. Repeating blood cultures during hospital stay: practice pattern at a teaching hospital and a proposal for guidelines. Clin Microbiol Infect 2004; 10:624-7

16 Wu AH. Reducing the inappropriate utilization of clinical laboratory tests. Conn Med 1997:61:15-21.

17 Wong ET. Improving laboratory testing: can we get physicians to focus on outcome? Clin Chem 1995;41:1241-7.

18 Zaat JO, van Eijk JT. General practitioners' uncertainty, risk preference, and use of laboratory tests. Med Care 1992;30:846-54.

19 Little $\mathbf{P}$, Cantrell T, Roberts L, et al. Why do GPs perform investigations? The medical and social agendas in arranging back X-rays. Fam Pract 1998; 15:264-5.

20 McDonald IG, Daly J, Jelinek VM, et al. Opening Pandora's box: the unpredictability of reassurance by a normal test result. BMJ 1996;313:329-32.

21 Bates DW, Goldman L, Lee TH. Contaminant blood cultures and resource utilization. The true consequences of false-positive results. JAMA 1991;265:365-9.

22 Rang M. The Ulysses syndrome. Can Med Assoc J 1972;106:122-3.

23 Fineberg HV, Pearlman LA. Low-cost medical practices. Annu Rev Public Health 1982;3:225-48.

24 Lewis S, Foreman J. Low-cost diagnostic technologies and clinical outcomes. The impact of inappropriate utilization. Int J Technol Assess Health Care 1997; 13:501-11.

25 Moloney TW, Rogers DE. Medical technology-a different view of the contentious debate over costs. N Engl J Med 1979;301:1413-19.

26 Thamer M, Fitzpatrick KJ, Perry S. Medical and surgical supply costs. Case study of a costly low-cost technology. Int J Technol Assess Health Care 1997; 13:526-36.

27 Oxman AD, Thomson MA, Davis DA, et al. No magic bullets: a systematic review of 102 trials of interventions to improve professional practice. Can Med Assoc J 1995; 153:1423-31.

28 Verstappen WH, ter Riet G, Dubois WI, et al. Variation in test ordering behaviour of GPs: professional or context-related factors? Fam Pract 2004;21:387-95.

29 Axt-Adam P, van der Wouden JC, van der DE. Influencing behavior of physicians ordering laboratory tests: a literature study. Med Care 1993:31:784-94

30 van Walraven $C$, Naylor CD. Do we know what inappropriate laboratory utilization is? A systematic review of laboratory clinical audits. JAMA 1998;280:550-8. 
31 Werner M. Appropriate utilization and cost control of the hospital laboratory: panel testing and repeat orders. Clin Chim Acta 1995;233:1-17.

32 Valenstein P, Leiken A, Lehmann C. Test-ordering by multiple physicians increases unnecessary laboratory examinations. Arch Pathol Lab Med 1988;112:238-41.

33 Tierney WM, McDonald CJ, Martin DK, et al. Computerized display of past test results. Effect on outpatient testing. Ann Intern Med 1987; 107:569-74.

34 Tierney WM, McDonald CJ, Hui SL, et al. Computer predictions of abnormal test results. Effects on outpatient testing. JAMA 1988;259:1194-8.

35 Bates DW, Kuperman G, Teich JM. Computerized physician order entry and quality of care. Qual Manag Health Care 1994;2:18-27.

36 Sittig DF, Stead WW. Computer-based physician order entry: the state of the art. J Am Med Inform Assoc 1994; 1:108-23.

37 Tierney WM, Miller ME, Overhage JM, et al. Physician inpatient order writing on microcomputer workstations. Effects on resource utilization. JAMA 1993;269:379-83.

38 Johnston ME, Langton KB, Haynes RB, et al. Effects of computer-based clinical decision support systems on clinician performance and patient outcome. A critical appraisal of research. Ann Intern Med 1994;120:135-42.

39 Bunting PS, van Walraven C. Effect of a controlled feedback intervention on laboratory test ordering by community physicians. Clin Chem 2004;50:321-6.

40 Grimshaw JM, Russell IT. Effect of clinical guidelines on medical practice: a systematic review of rigorous evaluations. Lancet 1993;342:1317-22.

41 Neilson EG, Johnson KB, Rosenbloom ST, et al. The impact of peer management on test-ordering behavior. Ann Intern Med 2004;141:196-204

42 Solomon DH, Hashimoto H, Daltroy L, et al. Techniques to improve physicians' use of diagnostic tests: a new conceptual framework. JAMA 1998;280:2020-7.

43 Huissoon AP, Carlton SA. Unnecessary repeat requesting of tests in a university teaching hospital immunology laboratory: an audit. J Clin Pathol 2002;55:78.

44 Lane SK, Gravel JW Jr. Clinical utility of common serum rheumatologic tests. Am Fam Physician 2002;65:1073-80.

45 Moder KG. Use and interpretation of rheumatologic tests: a guide for clinicians. Mayo Clin Proc 1996;71:391-6.

46 Tozzoli R, Bizzaro N, Tonutti E, et al. Guidelines for the laboratory use of autoantibody tests in the diagnosis and monitoring of autoimmune rheumatic diseases. Am J Clin Pathol 2002;117:316-24

47 Tampoia M, Fontana A, Di Serio F, et al. Application of a diagnostic algorithm in autoantibody testing: assessment of clinical effectiveness and economic efficiency. Clin Chim Acta 2003;333:181-3.

48 Gama R, Nightingale PG, Broughton PM, et al. Modifying the request behaviour of clinicians. J Clin Pathol 1992;45:248-9.

49 Blecher TE. Modifying the request behaviour of clinicians. J Clin Pathol 1992;45:742-3.

50 Kavanaugh A, Tomar R, Reveille J, et al. Guidelines for clinical use of the antinuclear antibody test and tests for specific autoantibodies to nuclear antigens. American College of Pathologists. Arch Pathol Lab Med 2000;124:71-81

51 loannidis JP, Katsifis GE, Stavropoulos ED, et al. Evaluation of the association of autoantibodies with mortality in the very elderly: a cohort study. Rheumatology (Oxford) 2003;42:357-61.

52 Shmerling RH. Rheumatic disease: choosing the most useful diagnostic tests. Geriatrics 1996;51:22-30, 32

53 Alvarez F, Berg PA, Bianchi FB, et al. International autoimmune hepatitis group report: review of criteria for diagnosis of autoimmune hepatitis. J Hepatol 1999;31:929-38.

54 Ben Ari Z, Czaja AJ. Autoimmune hepatitis and its variant syndromes. Gut 2001:49:589-94.

55 Czaja AJ, Carpenter HA. Histological findings in chronic hepatitis $\mathrm{C}$ with autoimmune features. Hepatology 1997;26:459-66.

56 Czaja AJ, Homburger HA. Autoantibodies in liver disease. Gastroenterology 2001;120:239-49.

57 Czaja AJ, Freese DK. Diagnosis and treatment of autoimmune hepatitis Hepatology 2002:36:479-7.

58 Johnson PJ, McFarlane IG. Meeting report: international autoimmune hepatitis group. Hepatology 1993; 18:998-1005.

59 Miyakawa H, Kawaguchi N, Abe K, et al. Serial changes of serum anti-M2 proteins in patients with primary biliary cirrhosis: a follow-up study by immunoblotting. Hepatol Res 1999;13:143-52.

60 Talwalkar JA, Lindor KD. Primary biliary cirrhosis. Lancet 2003;362:53-61.

61 Irvine WJ. Immunologic aspects of pernicious anemia. N Engl J Med 1965;273:432-8.

62 Toh BH, van Driel IR, Gleeson PA. Pernicious anemia. N Engl J Med 1997;337:1441-8.
63 Chapel HM. Consensus on diagnosis and management of primary antibody deficiencies. Consensus panel for the diagnosis and management of primary antibody deficiencies. BMJ 1994;308:581-5.

64 Anonymous. Consensus document for the diagnosis and management of patients with primary antibody immunodeficiencies. London: The Marks and Spencer Publications Unit of the Royal College of Pathologists, 1995

65 European Group of Tumour Markers (ETGM). Consensus recommendations. Anticancer Res 1999;19:2784-820.

66 Singapore Ministry of Health-National Government Agency (non-US), ed. Chronic hepatitis B infection. Singapore: National Guideline Clearinghouse, 2003.

67 Duffy MJ, McGuire P, McSweeney J. Guidelines for the use of tumour markers, 2nd ed. Association of Clinical Biochemists in Ireland, 2000 (http:// www.acbi.ie/acbi-tmk.html).

68 Gebo KA, Chander G, Jenckes MW, et al. Screening tests for hepatocellular carcinoma in patients with chronic hepatitis $C$ : a systematic review. Hepatology 2002;36:S84-92.

69 National Cancer Institute. Hepatocellular cancer: screening. Last accessed February 2005 (http://www.cancer.gov/cancerinfo/pdq/screening/ hepatocellular/healthprofessional).

70 Clinical practice guidelines for the use of tumor markers in breast and colorectal cancer. Adopted on May 171996 by the American Society of Clinical Oncology. J Clin Oncol 1996;14:2843-77.

71 Tumour markers in gastrointestinal cancers-EGTM recommendations. European group on tumour markers. Anticancer Res 1999;19:2811-15.

72 ESMO minimum clinical recommendations for diagnosis, treatment and follow-up of advanced colorectal cancer. Ann Oncol 2001;12:1055.

73 ESMO minimum clinical recommendations for diagnosis, adjuvant treatment and follow-up of colon cancer. Ann Oncol 2001;12:1053-4.

74 Anthony T, Simmang C, Hyman N, et al. Practice parameters for the surveillance and follow-up of patients with colon and rectal cancer. Dis Colon Rectum 2004;47:807-17.

75 Bast RC Jr, Ravdin P, Hayes DF, et al. 2000 update of recommendations for the use of tumor markers in breast and colorectal cancer: clinical practice guidelines of the American Society of Clinical Oncology. J Clin Oncol 2001;19:1865-78

76 Compton CC, Fielding LP, Burgart $\amalg$, et al. Prognostic factors in colorectal cancer. College of American Pathologists consensus statement 1999. Arch Pathol Lab Med 2000;124:979-94.

77 Watine J, Friedberg B. Laboratory variables and stratification of metastatic colorectal cancer patients: recommendations for therapeutic trials and for clinical practice guidelines. Clin Chim Acta 2004;345:1-15

78 ESMO minimum clinical recommendations for diagnosis, adjuvant treatment and follow-up of primary breast cancer. Ann Oncol 2001;12:1047-48.

79 Tumour markers in prostate cancer: EGTM recommendations. European group on tumour markers. Anticancer Res 1999;19:2799-801.

80 Bates DW, Boyle DL, Rittenberg E, et al. What proportion of common diagnostic tests appear redundant? Am J Med 1998;104:361-8.

81 Eisenberg JM. Doctors' decisions and the cost of medical care. Ann Arbor, MI: Health Administration Press, 1986.

82 Davidoff F, Goodspeed R, Clive J. Changing test ordering behavior. A randomized controlled trial comparing probabilistic reasoning with costcontainment education. Med Care 1989;27:45-58.

83 Mozes B, Lubin D, Modan B, et al. Evaluation of an intervention aimed at reducing inappropriate use of preoperative blood coagulation tests. Arch Intern Med 1989:149:1836-8.

84 Thompson RS, Kirz HL, Gold RA. Changes in physician behavior and cost savings associated with organizational recommendations on the use of "routine" chest X rays and multichannel blood tests. Prev Med 1983; 12:385-96

85 Zaat JO, van Eijk JT, Bonte HA. Laboratory test form design influences test ordering by general practitioners in the Netherlands. Med Care 1992;30: 189-98.

86 Durand-Zaleski I, Rymer JC, Roudot-Thoraval F, et al. Reducing unnecessary laboratory use with new test request form: example of tumour markers. Lancet 1993:342:150-3.

87 Wong ET, McCarron MM, Shaw ST Jr. Ordering of laboratory tests in a teaching hospital. Can it be improved? JAMA 1983;249:3076-80.

88 Novich M, Gillis L, Tauber Al. The laboratory test justified. An effective means to reduce routine laboratory testing. Am J Clin Pathol 1985;84:756-9.

89 Dixon RH, Laszlo J. Utilization of clinical chemistry services by medical house staff. An analysis. Arch Intern Med 1974;134:1064-7.

90 Eisenberg JM. An educational program to modify laboratory use by house staff. J Med Educ 1977;52:578-81.

91 van Walraven C, Goel V, Chan B. Effect of population-based interventions on laboratory utilization: a time-series analysis. JAMA 1998;280:2028-33. 